\title{
Skin Nodular Basal Cell Carcinoma
}

National Cancer Institute

\section{Source}

National Cancer Institute. Skin Nodular Basal Cell Carcinoma. NCI Thesaurus. Code C62282.

A basal cell carcinoma of the skin that often appears as elevated nodules which may become ulcerated. 